\title{
Breastfeeding and the Risk of Illness among Young Children in Rural China
}

\author{
Shanshan Li ${ }^{1}$, Ai Yue ${ }^{1, *}$, Cody Abbey ${ }^{2}$, Alexis Medina ${ }^{2}$ and Yaojiang Shi ${ }^{1}$ \\ 1 Center for Experimental Economics in Education (CEEE), Shaanxi Normal University, Xi'an 710119, China; \\ lishanshan.ceee@gmail.com (S.L.); shiyaojiang7@gmail.com (Y.S.) \\ 2 Rural Education Action Program, Freeman Spogli Institute for International Studies, Stanford University, \\ Palo Alto, CA 94305, USA; cjabbey88@gmail.com (C.A.); amedina5@stanford.edu (A.M.) \\ * Correspondence: yueai@163.com; Tel.: +1-500-296-0502
}

Received: 1 November 2018; Accepted: 26 December 2018; Published: 7 January 2019

check for updates

\begin{abstract}
Poor rural areas in China exhibit the country's highest rates of child mortality, often stemming from preventable health conditions such as diarrhea and respiratory infection. In this study, we investigate the association between breastfeeding and disease among children aged 6-24 months in poor rural counties in China. To do this, we conducted a longitudinal, quantitative analysis of socioeconomic demographics, health outcomes, and breastfeeding practices for 1802 child-caregiver dyads across 11 nationally designated poverty counties in southern Shaanxi Province in 2013-2014. We found low rates of continued breastfeeding that decreased as children developed: from 58.2\% at $6-12$ months, to $21.6 \%$ at $12-18$ months, and finally to $5.2 \%$ at $18-24$ months. These suboptimal rates are lower than all but one other country in the Asia-Pacific region. We further found that only $18.3 \%$ of children 6-12 months old met the World Health Organization (WHO)-recommended threshold for minimum dietary diversity, defined as consuming four or more of seven specific food groups. Breastfeeding was strongly associated with lower rates of both diarrhea and cough in bivariate and multivariate analyses. As the first analysis to use longitudinal data to examine the relationship between continued breastfeeding and child illness in China, our study confirms the need for programmatic interventions that promote continued breastfeeding in order to improve toddler health in the region.
\end{abstract}

Keywords: breastfeeding; infants; illness; rural China

\section{Introduction}

Breastfeeding is widely recognized as the best feeding practice for early child development [1]. During the first two years of a child's life, breastfeeding can positively contribute to both short- and long-term health outcomes [2,3]. According to the World Health Organization (WHO), exclusive breastfeeding reduces infant mortality due to common childhood diseases such as diarrhea or pneumonia, both by increasing resistance to and allowing for a quicker recovery from such diseases. For children aged 6 to 23 months, continued breastfeeding reduces their exposure to contaminated food and liquids, and reduces the prevalence of diarrhea and cough [4,5]. Breastfeeding has also been associated with lower rates of other common childhood diseases, including upper respiratory tract illnesses [6]. Based on such evidence, the WHO recommends that children be exclusively breastfed for the first six months after birth, with breastfeeding continuing up to 2 years of age (or even later) together with the introduction of appropriate complementary foods [7].

A considerable amount of literature shows that rates of breastfeeding in rural China are dismally low, both in terms of exclusive breastfeeding in the first 6 months (21\% to 29\%) [8-11], and in terms of continued breastfeeding, defined as breastfeeding from 6-24 months of age. The rate of continued 
breastfeeding is $29.7 \%$ at 12 months, $7.9 \%$ at 18 months, and only $2.3 \%$ at 24 months [12]. A study conducted in 26 poor rural counties in 12 central and western provinces of China found that while just over half (55.5\%) of children had continued breastfeeding for 1 year, only $9.4 \%$ of children had continued breastfeeding for 2 years [9]. These proportions lag behind the overall rates of continued breastfeeding in developing countries, which are $86 \%$ for children aged $6-11$ months, and $68 \%$ for children aged 12-23 months [13].

In addition to encouraging continued breastfeeding, the WHO guidelines also indicate that complementary foods should be gradually introduced, beginning at around 6 months of age, and that by 1 year of age they should constitute the majority of a child's diet [7,14]. Many studies have noted the important role that complementary foods play in shaping children's health and nutrition $[15,16]$. Evidence suggests that higher dietary diversity may reflect better diets and diets that are more likely to meet daily energy and nutrient requirements $[17,18]$. In one study in Bangladesh, when continued breastfeeding was accompanied with complementary foods, there was a reduction in clinical malnutrition [19]. However, other evidence has shown either no link between continued breastfeeding and malnutrition [20], or that children with continued breastfeeding were less likely to consume more food items, suggesting a negative link between breastfeeding and dietary diversity [21]. Beyond a single, very small, geographically limited study [22], little is known about dietary diversity among young children in rural China.

Concurrent with the low rates of breastfeeding are studies showing the worrisome status of child health in China, especially in rural areas. Although evidence has shown that China has achieved a rapid reduction in child mortality in recent decades, this masks great disparities across regions [23]. Children living in poor rural areas have significantly worse health outcomes than their wealthier, urban counterparts $[24,25]$. Evidence shows that more than half $(69.5 \%)$ of rural children under 2 years old suffer from diarrhea [26]. This proportion is higher than that observed in developing countries $(40.3-51 \%)[27,28]$. The prevalence of fever and cough among children aged $6-11$ months is also high in rural China, at $49.7 \%$ and $59.5 \%$, respectively [22]. These rates are not only higher than those observed in urban areas in China (12.2\% for fever, $19.9 \%$ for cough) $[5,29]$, but also higher than in some developing countries (11-19.5\% for cough; $12-51 \%$ for fever) [5,30]. This is especially alarming, considering that China is now officially classified as a middle-income country [31].

Could the low rates of continued breastfeeding be connected with the high prevalence of poor child health outcomes in China? While several studies (mentioned above) have measured the prevalence of breastfeeding among various populations within China [9-12], to our knowledge, existing studies have yet to explore the relationship between the low rate of continued breastfeeding and child health outcomes, especially in poor rural areas.

The overall objective of this paper is to describe the status quo of child health status and early childhood feeding behaviors in our sample and investigate the association between continued breastfeeding and the incidence of child health outcomes (i.e., fever, diarrhea, upper respiratory infection, and cough) among children aged 6-24 months in poor, rural counties in China.

\section{Materials and Methods}

\subsection{Sample Selection}

Our study was conducted in 2013 in 11 nationally designated poverty counties located in southern Shaanxi Province, China. The area is predominantly Han Chinese and had a per capita annual income of about 6502 RMB (1050 USD) in 2013 [32], over 25\% lower than the 8896 RMB (1437 USD) national rural average in the same year [33]. From each of these 11 counties, all townships (the middle level of administration between county and village) were selected to participate in the study. There were two exceptions to this rule: we excluded the one township in each county that housed the county seat, and we excluded any townships that did not have any villages with a population of 800 or more. In total, according to these criteria, 174 townships were included in the study. 
The sample villages were originally selected as follows. To meet the power requirements of a larger, interventional study (not reported in this paper) [34], we required a minimum of five children in each township. With this requirement in mind, we first randomly selected one village (with a population of 800 or more) from each township to participate. A list of all registered births over the past 12 months was obtained from the local family planning official in each village. All children in our desired age range (6-12 months) were enrolled in the study. If a village had fewer than five children in our desired age range, we randomly selected an additional village in the same township for inclusion in the study and continued to randomly select additional villages until five children per township had been found.

In total, we included 1802 children aged 6-12 months at the time of the baseline survey. We conducted two additional rounds of follow-up data collection. The children were 12-18 months old during the first follow-up survey, and 18-24 months old during the second follow-up survey.

\subsection{Data Collection}

Teams of trained enumerators collected socioeconomic information from all households participating in the study. We collected both household-level and child-specific data. At the household level, the primary caregiver (typically either the child's mother or grandmother) was identified in each family as the individual who was most responsible for the child's care. She (or he) was administered a detailed survey on household characteristics, including maternal age and education, and whether the family was receiving Minimum Living Standard Guarantee Payments (a form of government welfare for the lowest-income families nationwide). She also provided information on household assets, which was used to calculate the household socioeconomic status (SES) index using principal component analysis [35]. Questions included whether or not the household owned or had access to tap water, a heater, a refrigerator, a washing machine, a computer, internet, a motorcycle, a car, a truck, a flushing toilet, and the approximate housing value. At the individual level, the primary caregiver also provided information on each child's gender and birth order. The child's age was obtained from his or her birth certificate.

The survey also included a detailed module on feeding practices, based on the "Indicators assessing children and young child feeding practices" [36,37] complied by the WHO and others in the international community. We asked caregivers whether the child was still being breastfed at the time of survey administration, as well as whether they were being fed formula. The main predictor was the status of continued breastfeeding, which was defined as whether the child was still being breastfed at the time of each survey round. A child was considered to be exclusively breastfed if he or she was fed nothing but breast milk on the day prior to survey administration. We also provided caregivers with a list of seven different food categories: 1 . grains, roots, and tubers; 2 . legumes and nuts; 3 . dairy products; 4 . flesh foods (meat, fish, poultry, and liver/organ meats) 5. eggs; 6. vitamin-A-rich fruits and vegetables; 7 . other fruits and vegetables. We then asked caregivers to identify which of the seven food types their child had consumed the previous day. Following WHO guidelines [38], a child was defined as having met the minimum dietary diversity requirements if they had consumed foods from four or more different categories.

The primary outcomes of interest for this study were incidence of fever, diarrhea, cold, and cough among sample children. These were collected through caregiver recall of symptoms in the month prior to survey administration. All variables used in our statistical analysis are presented in Table A1.

\subsection{Ethical Approval}

Ethical approval was provided by the Institutional Review Board (IRB) of Stanford University (Protocol ID 25734) and from the Ethical Review Board of Sichuan University (Protocol ID 2013005-01). All participants gave oral consent for both their own and their children's involvement in the study. 


\subsection{Statistical Analysis}

Descriptive statistics, including patterns of breastfeeding and basic background characteristics, were reported. Multivariate regressions with random effects at the household level were used to control for intra-household correlation across survey waves. Building on the related literature [39,40], we considered the household level, child-specific characteristics, and child's dietary diversity described above as potential confounders of association between breastfeeding and child illness. Confounding factors were controlled for in the final model. In estimating the correlation between continued breastfeeding and health problems, we used ordinary least squares (OLS), including a set of covariates in a regression on the health status of children. We first ran an unadjusted regression (1):

$$
Y_{i j}=\alpha+\beta * B F S_{i j}+\varepsilon_{i j}
$$

The dependent variable $Y_{i j}$ indicates the rate of diarrhea/cough/fever/cold of children $i$ in village $j$, which equals to 1 if the child had experienced diarrhea/cough/fever/cold in the month prior to survey administration. $B F S_{i}$ indicates whether the child was still being breastfed at the time of each survey round, which indicates the caregiver feeding practice for child $i$. Standard errors are clustered at the village level. $\varepsilon_{i j}$ is an error term.

To control for the potential confounding effects of child and family characteristics, we ran a multivariate analysis building on Equation (1) above by including a vector of control variables.

$$
Y_{i j}=\alpha+\beta * B F S_{i j}+\gamma X_{i j}+\varepsilon_{i j}
$$

The term $X_{i j}$ is a vector of covariates including the child's dietary diversity, child characteristics (age, gender, sibling, etc.) and household characteristics (maternal education level, maternal age, etc.).

In all Equations (1)-(2), we computed heteroskedasticity-robust standard errors (adjusted for clustering at village level).

All statistical analyses were carried out using Stata 14.2. $p$-values below 0.05 were considered statistically significant [9].

\section{Results}

\subsection{Attrition Across Survey Waves}

The baseline sample included 1802 children. We were able to follow up with 1592 children after 6 months (first follow-up, when children were aged 12-18 months) and with 1499 children after 12 months (second follow-up, when children were aged 18-24 months). The attrition of the sample was therefore $11.7 \%$ after 6 months, and $16.8 \%$ after 12 months. Attrition was random and not associated with variables of interest. Overall, attrition was low between the time of the baseline to the final survey, and not correlated with any key outcome variables (Table A2).

\subsection{Socioeconomic and Demographic Characteristics of Participants}

The basic socioeconomic and demographic characteristics of study participants are reported in Table 1. Children were aged 6-12 months at the time of the baseline survey, and the sample was evenly distributed across ages (data not shown). The vast majority of children in our sample (79.3\%) did not have siblings at baseline. The mother was the primary caregiver for $82.4 \%$ of the children in the sample when the children were 6-12 months old, though this percentage decreased to $63.0 \%$ when the children were 18-24 months old, as mothers out-migrated (data not shown). The majority of sample mothers $(78.7 \%)$ had completed 9 years of schooling or less, and around half $(50.1 \%)$ were over 25 years of age. About one quarter $(23.6 \%)$ of sampled families reported receiving Minimum Living Standard Guarantee payments. 
Table 1. Summary statistics of sample children aged 6-12 months in rural China $(n=1802)$.

\begin{tabular}{|c|c|c|}
\hline & Frequency $(n)$ & Percentage $(\%)$ \\
\hline \multicolumn{3}{|l|}{ Panel A: Child Characteristics } \\
\hline (1) Male & 949 & 52.7 \\
\hline (2) Has Siblings & 373 & 20.7 \\
\hline (3) Premature Birth & 198 & 11.0 \\
\hline (4) Mother is the Primary Caregiver & 1477 & 82.4 \\
\hline \multicolumn{3}{|l|}{ Panel B: Household Characteristics } \\
\hline (5) Maternal Age $>25$ & 903 & 50.1 \\
\hline \multicolumn{3}{|l|}{ (6) Years of Maternal Education } \\
\hline$\leq 6$ years & 497 & 27.6 \\
\hline$>6$ and $\leq 9$ years & 1008 & 55.9 \\
\hline$>9$ years & 297 & 16.5 \\
\hline \multicolumn{3}{|l|}{ (7) Years of Paternal Education } \\
\hline$\leq 6$ years & 413 & 22.9 \\
\hline$>6$ and $\leq 9$ years & 1005 & 55.8 \\
\hline$>9$ years & 384 & 21.3 \\
\hline (8) Father at Home & 790 & 43.8 \\
\hline (9) Grandmother is Healthy & 761 & 42.2 \\
\hline \multicolumn{3}{|l|}{ (10) Years of Grandmother Education } \\
\hline$\leq 6$ years & 1491 & 82.7 \\
\hline$>6$ and $\leq 9$ years & 263 & 14.6 \\
\hline$>9$ years & 48 & 2.7 \\
\hline \multicolumn{3}{|l|}{ (11) Asset Index } \\
\hline Poorest tercile & 600 & $-1.2 \pm 0.4$ \\
\hline Middle tercile & 601 & $-0.2 \pm 0.3$ \\
\hline Wealthiest tercile & 601 & $1.4 \pm 0.7$ \\
\hline $\begin{array}{l}\text { (12) Family Receives Minimum Living } \\
\text { Standard Guarantee Payments }\end{array}$ & 425 & 23.6 \\
\hline
\end{tabular}

Notes: These are the descriptive statistics of child and household characteristics for infants aged 6-12 months. The table shows the mean and standard deviation of infant and household characteristics for the full sample. The variable "Father at Home" equals 1 if, at the time of the baseline survey, the father had been at home for a majority of the previous six months, and 0 otherwise. "Grandmother Healthy" is based on self-reported general health. The asset index was constructed using polychoric principal components on the following variables: tap water, toilet, water heater, washing machine, computer, fridge, air conditioning, motor or electronic bicycle, and car.

\subsection{Feeding Behaviors of Children in Rural China}

In Table 2, we show that fewer than $1 \%$ of children were being exclusively breastfed at the time of the baseline survey, when they were 6-12 months old ( $0.33 \%)$. No children older than 12 months were exclusively breastfed. The rate of any breastfeeding was low across all age groups, and showed a decreasing trend as children aged, with the highest rate at baseline $(58.2 \%)$, decreasing to $21.6 \%$ when children were 12-18 months old, and further decreasing to 5.2\% when the children were 18-24 months of age. As the sample of children who were still being breastfed after 18 months was too small to be meaningful (5.2\%), we did not include data from the second follow-up survey in any of our remaining analyses (when children were 18-24 months old). 
Table 2. Feeding behaviors among sample children aged 6-24 months in rural China $(n=4893)$.

\begin{tabular}{|c|c|c|c|}
\hline & 6-12 Months & 12-18 Months & 18-24 Months \\
\hline & $\begin{array}{l}\text { Number }(\%) \\
\text { (1) }\end{array}$ & $\begin{array}{l}\text { Number }(\%) \\
\text { (2) }\end{array}$ & $\begin{array}{c}\text { Number }(\%) \\
\text { (3) }\end{array}$ \\
\hline (1) Any Breastfeeding & $1049(58.2)$ & $343(21.5)$ & $78(5.2)$ \\
\hline (1.1) Exclusive Breastfeeding & $6(0.3)$ & $0(0.0)$ & $0(0.0)$ \\
\hline (1.2) Continued breastfeeding, & $779(43.2)$ & $240(15.1)$ & $49(3.3)$ \\
\hline without Formula & & & \\
\hline $\begin{array}{l}\text { (1.3) Continued breastfeeding, } \\
\text { with Formula/Food }\end{array}$ & $264(14.7)$ & $103(6.4)$ & $29(1.9)$ \\
\hline \multicolumn{4}{|l|}{ (2) Any Formula-fed } \\
\hline (2.1) Formula with Food & $733(40.7)$ & $1033(64.9)$ & $1086(72.5)$ \\
\hline (3) Food Alone & $20(1.1)$ & $216(13.6)$ & $335(22.4)$ \\
\hline (4) Total & 1802 & 1592 & 1499 \\
\hline
\end{tabular}

Notes: There are three main types of feeding behaviors among the sample ("Any Breastfeeding", "Any Formula-fed" and "Food Alone"). "Any Breastfeeding" includes all sample children who are consuming breast milk. "Exclusive Breastfeeding" refers to children who consume nothing but breast milk. Sample children who were fed breast milk and food (but no formula) were classified as "Non-Exclusive Breastfeeding without Formula". Sample children who were fed breast milk, food, and formula were classified as "Non-Exclusive Breastfeeding with Formula". No sample children were fed breast milk and formula but no food. "Any Formula-fed" refers to sample children who were fed formula with food. No sample children were fed formula alone. All children in our desired age range (6-12 months) were enrolled in baseline survey. This was defined so as to include children who were as young as 6 months and zero days (day of their 6-month birthday), as well as children who were as old as 12 months and 30 days (one day before their 13-month birthday). This means that the sample children were 12-18 months old (12 months and zero days, and 18 months and 30 days) during the first follow-up survey (6 months after the baseline survey), and 18-24 months old during the second follow-up survey (12 months after the baseline survey).

\subsection{Dietary Diversity in Children Aged 6-18 Months in Rural China}

Table 3 shows the dietary diversity of children in our sample. Overall, children aged 6-12 months only consumed an average of 3.0 types of food on the day prior to survey administration. This is significantly lower than the recommended minimum diversity threshold set by WHO, which is defined as four or more of the seven food groups [38]. Only $18.3 \%$ of children aged 6-12 months met the minimum dietary diversity threshold. By the time the children reached 12-18 months of age, however, this ratio had increased substantially to $71.8 \%$. We found that children who were breastfed had significantly less diverse diets than children who were not breastfed (including both those who had formula with food and those who ate food alone). This was true across both age groups. From this table, it can also be seen that the composition of the children's diets became more diverse as they grew older, from 6-12 months to 12-18 months. 
Table 3. Descriptive statistics of dietary diversity in infants aged 6-18 months in rural China $(n=3394)$.

\begin{tabular}{lcccc}
\hline & \multicolumn{2}{c}{$\mathbf{6 - 1 2}$ Months } & \multicolumn{2}{c}{ 12-18 Months } \\
\cline { 2 - 5 } & Percent/Mean & $\boldsymbol{n}$ & Percent/Mean & $\boldsymbol{n}$ \\
\hline $\begin{array}{l}\text { Percentage of children who } \\
\text { met the minimum dietary }\end{array}$ & 18.3 & 330 & 71.8 & 1143 \\
diversity threshold & & & & \\
\hline Mean number of food types child consumed & & & \\
yesterday & 3.0 & 1802 & 4.2 & 1592 \\
\hline (1) Full sample & 2.8 & 1049 & 3.7 & 343 \\
(2) Breastfeeding sample & 3.3 & 753 & 4.4 & 1249 \\
(3) Non-Breastfeeding sample & 3.3 & 733 & 4.5 & 1033 \\
(3.1) Formula with food & 3.0 & 20 & 4.1 & 216 \\
(3.2) Food alone & & & & \\
\hline p-values & $<0.01$ & & $<0.01$ & \\
\hline (1) Difference (2)-(3) & $<0.01$ & & $<0.01$ & \\
(2) Difference (2)-(3.1) & 0.35 & & $<01$ & \\
(6) Difference (2)-(3.2) & & & & \\
\hline
\end{tabular}

Notes: The unit for the dietary diversity data is the mean number of the following food categories fed to the child on the day prior to survey administration: 1 . grains, roots, and tubers; 2 . legumes and nuts; 3 . dairy products; 4 . flesh foods (meat, fish, poultry, and liver/organ meats) 5. eggs; 6. vitamin-A-rich fruits and vegetables; 7 . other fruits and vegetables. There is no "formula alone" or "formula with breastfeeding but without food".

\subsection{Health Status of Children in Rural China}

Table 4 summarizes the incidence of fever, diarrhea, cold, and cough among sample children, showing that the incidence of illness decreased as children aged. Incidence of diarrhea decreased from $36.9 \%$ when the children were $6-12$ months old, to $30.4 \%$ when they were $12-18$ months old. Similarly, the incidence of cough decreased from $45.5 \%$ to $42.0 \%$ across the same time period. The incidence of fever decreased from $30.0 \%$ to $28.5 \%$, and the incidence of cold decreased from $56.9 \%$ to $54.8 \%$. 
Table 4. Correlation between breastfeeding and health outcomes in children aged 6-18 months in rural China $(n=3394)$.

\begin{tabular}{|c|c|c|c|c|c|c|c|c|}
\hline & \multicolumn{3}{|c|}{ 6-12 Months } & \multirow{3}{*}{$\begin{array}{c}\text { Difference } \\
p \text {-Value } \\
\text { (2)-(3) }\end{array}$} & \multicolumn{3}{|c|}{ 12-18 Months } & \multirow{3}{*}{$\begin{array}{c}\begin{array}{c}\text { Difference } \\
p \text {-Value }\end{array} \\
(5)-(6)\end{array}$} \\
\hline & \multirow{2}{*}{$\begin{array}{c}\text { Total } \\
\text { (1) } \\
\end{array}$} & \multicolumn{2}{|c|}{ Breastfeeding } & & \multirow{2}{*}{$\begin{array}{c}\text { Total } \\
(4) \\
\end{array}$} & \multicolumn{2}{|c|}{ Breastfeeding } & \\
\hline & & $\begin{array}{l}\text { Yes } \\
\text { (2) }\end{array}$ & $\begin{array}{l}\text { No } \\
\text { (3) }\end{array}$ & & & $\begin{array}{l}\text { Yes } \\
\text { (5) }\end{array}$ & $\begin{array}{l}\text { No } \\
\text { (6) }\end{array}$ & \\
\hline (1) Child had a fever in the past month & $541(30.0)$ & $28.8(302)$ & $31.7(239)$ & 0.18 & $428(28.5)$ & $27.1(93)$ & $26.8(335)$ & 0.53 \\
\hline (2) Child had diarrhea in the past month & $664(36.9)$ & $33.2(348)$ & $42.0(316)$ & $<0.01$ & $456(30.4)$ & $25.1(86)$ & $29.6(370)$ & 0.02 \\
\hline (3) Child had a cold in the past month & $1025(56.9)$ & $57.9(607)$ & $55.5(418)$ & 0.32 & $823(54.8)$ & $54.2(186)$ & $51.0(637)$ & 0.82 \\
\hline (4) Child had a cough in the past month & $819(45.5)$ & $43.3(454)$ & $48.5(365)$ & 0.03 & $631(42.0)$ & $34.4(118)$ & $41.1(513)$ & $<0.01$ \\
\hline$n$ & 1802 & 1049 & 753 & & 1592 & 343 & 1249 & \\
\hline
\end{tabular}

Notes: Breastfeeding includes both exclusive breastfeeding and non-exclusive breastfeeding, with or without formula/food. 


\subsection{Links between Feeding Behavior and Health Status of Children}

Next, we investigated whether there was a correlation between feeding behavior and child health status. We found that breastfed children had lower rates of both diarrhea and cough, both at 6-12 months and at 12-18 months (Table 4). However, we found no differences in incidence of fever or cold.

In order to further examine the relationship between feeding behavior and the health status of children, we ran a series of multivariate regressions controlling for children, maternal, and household characteristics, presented in Table 5 . We found that the multivariate analysis results were consistent with the findings of the bivariate analysis; that is, children who were breastfed between 6 and 18 months had lower incidence of both diarrhea and cough. Specifically, in households with continued breastfeeding, the incidence of diarrhea was $11.9 \%$ lower than that of weaned children, while the incidence of cough was $7.0 \%$ lower. However, as in the bivariate analysis, there was no significant correlation between continued breastfeeding and incidence of either fever or cold.

Table 5. Multivariate analysis: Correlations between breastfeeding and health outcomes in children aged 6-18 months in rural China.

\begin{tabular}{|c|c|c|}
\hline & $\begin{array}{c}\text { OLS } \\
(\mathbf{1})\end{array}$ & $\begin{array}{c}\text { OLS } \\
(2)\end{array}$ \\
\hline (1) Child had a fever in the past month & $\begin{array}{l}-0.017 \\
(0.018)\end{array}$ & $\begin{array}{c}-0.014 \\
(0.021)\end{array}$ \\
\hline$n$ & 3394 & 3394 \\
\hline (2) Child had diarrhea in the past month & $\begin{array}{c}-0.072 * \\
(0.017)\end{array}$ & $\begin{array}{c}-0.119 \text { ** } \\
(0.020)\end{array}$ \\
\hline$n$ & 3394 & 3394 \\
\hline (3) Child had a cold in the past month & $\begin{array}{c}0.027 \\
(0.021)\end{array}$ & $\begin{array}{c}0.004 \\
(0.024)\end{array}$ \\
\hline$n$ & 3394 & 3394 \\
\hline (4) Child had a cough in the past month & $\begin{array}{c}-0.058 \text { ** } \\
(0.021)\end{array}$ & $\begin{array}{c}-0.070 \text { ** } \\
(0.024)\end{array}$ \\
\hline 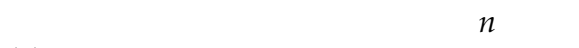 & 3394 & 3394 \\
\hline (5) Dietary Diversity & & Yes \\
\hline (6) Controls & & Yes \\
\hline (7) Enumerator fixed effect & & Yes \\
\hline (8) Wave dummies & Yes & Yes \\
\hline
\end{tabular}

Notes: Column (1) shows the coefficients on breastfeeding in an ordinary least squares (OLS) regression pooling data across waves, controlling for survey wave dummies. Column (2) shows coefficients from pooled OLS regressions additionally controlling for the child's dietary diversity and baseline controls (child age, gender, whether the child was premature, whether the child has siblings, maternal age, maternal educational level, paternal educational level, paternal migration status, health of the child's grandmother, educational level of the child's grandmother, asset index, and whether the household receives Minimum Living Standard Guarantee payments). Standard errors are clustered at the village level. $N$ is the total number of observations in each regression. ${ }^{*}$ indicates significance at $5 \%$; ** indicates significance at $1 \%$ after adjusting for multiple hypotheses, using the step-down procedure of Romano and Wolf (2005) to control the familywise error rate (FWER).

When comparing the association between breastfeeding and rate of illness across the age group (Table 6), we found that the results were consistent across both age groups. The rate of diarrhea was significantly lower for breastfed children at both 6-12 months and 12-18 months of age when compared to non-breastfed children. Breastfed children also had significantly lower rates of cough at 12-18 months (though not at 6-12 months). In addition, across both age groups, breastfeeding was not significantly correlated with fever or cold. 
Table 6. Multivariate analysis: Correlations between breastfeeding and health outcomes in infants aged 6-18 months in rural China.

\begin{tabular}{|c|c|c|c|c|}
\hline & \multicolumn{2}{|c|}{ 6-12 Months } & \multicolumn{2}{|c|}{ 12-18 Months } \\
\hline & (1) & (2) & (3) & (4) \\
\hline $\begin{array}{l}\text { (1) Child had a fever in the } \\
\text { past month }\end{array}$ & $-0.030(0.022)$ & $-0.25(0.029)$ & $0.003(0.026)$ & $-0.003(0.035)$ \\
\hline $\begin{array}{l}\text { (2) Child had diarrhea in the } \\
\text { past month }\end{array}$ & $-0.088 *(0.023)$ & $-0.118 *(0.028)$ & $-0.046(0.026)$ & $-0.118 *(0.034)$ \\
\hline $\begin{array}{l}\text { (3) Child had a cold in the past } \\
\text { month }\end{array}$ & $0.024(0.025)$ & $-0.003(0.030)$ & $0.032(0.033)$ & $0.013(0.041)$ \\
\hline $\begin{array}{l}\text { (4) Child had a cough in the } \\
\text { past month }\end{array}$ & $-0.052(0.028)$ & $-0.052(0.032)$ & $\begin{array}{l}-0.067^{* *} \\
(0.031)\end{array}$ & $\begin{array}{l}-0.094^{* *} \\
(0.038)\end{array}$ \\
\hline (5) Dietary Diversity & & Yes & & Yes \\
\hline (6) Controls & & Yes & & Yes \\
\hline (7) Enumerator fixed effect & & Yes & & Yes \\
\hline (8) Observations & 1802 & 1802 & 1592 & 1592 \\
\hline
\end{tabular}

Notes: Column (1) shows the coefficients on breastfeeding in an OLS regression pooling data across waves, controlling for survey wave dummies. Column (2) shows coefficients from pooled OLS regressions, additionally controlling for child's dietary diversity and baseline controls (child age, gender, whether the child was premature, whether the child has siblings, maternal age, maternal educational level, paternal educational level, paternal migration status, health of the child's grandmother, educational level of the child's grandmother, asset index, and whether the household receives Minimum Living Standard Guarantee payments). Standard errors are clustered at the village level. * indicates significance at $1 \%$ after adjusting for multiple hypotheses using the step-down procedure of Romano and Wolf (2005) to control the familywise error rate (FWER); ${ }^{* *}$ indicates significance at $5 \%$.

\section{Discussion}

This study shows that the practice of continued breastfeeding for children between 6 and 24 months in rural China is suboptimal. The rate of continued breastfeeding for children aged 6 to 12 months old was only $58.2 \%$, and declined to $5.2 \%$ for children aged 18 to 24 months. WHO guidelines clearly state that both of these rates should be $100 \%$. These rates of continued breastfeeding are lower than almost all other countries in the Asia-Pacific region, with only one other country-Thailand—reporting a lower rate of continued breastfeeding at one year of age (32\%) [41].

Our study also sheds light on the degree of dietary diversity among children in rural China, suggesting that their diets may be insufficiently diverse. Based on available evidence, complementary foods should be introduced to children at 6 months of age, as dietary diversity is strongly and consistently associated with all measures of nutritional status [42]. In our data, however, we find that the average number of food groups consumed is 2.5 for children aged 6-12 months and 3.2 for children aged 12-18 months-significantly lower than the minimum threshold set by the WHO. Interestingly, children who were not breastfed had higher dietary diversity than those who were (a phenomenon which has been documented by previous research [42]), though the level of dietary diversity was still insufficient regardless of breastfeeding status. This result may stem from a variety of different reasons. One important factor may be lack of access to information about child feeding practices. One qualitative study of caregiver feeding practices in rural China found that many rural caregivers lacked information on best feeding practices for their young children, and that they largely believed that as long as a child was not hungry, he or she was getting adequate nutritional intake [43]. If children who are breastfed feel fuller longer, then their caregivers may feel less urgency in introducing more and more varied complementary foods. Household income may also be a factor. Since breastfeeding is sometimes seen as a low-cost alternative to formula feeding, it may be that the poorer families are engaging in continued breastfeeding, and are therefore also less likely to have high levels of dietary diversity due to income constraints. A related issue may be that of migration. If a mother out-migrates from home for employment opportunities, she is substituting a higher household income (via remittances) for lost breastfeeding opportunities.

We note that the WHO urges researchers to use caution in comparing dietary diversity between breastfed and non-breastfed samples, due to the possibility that non-breastfed children may be 
consuming higher levels of animal milk as a substitute for breast milk. In our sample, however, we found no difference in dairy consumption between breastfed and non-breastfed children (data not shown), and therefore have no reason to believe that differences in dairy consumption may be influencing our results.

Despite lower dietary diversity, the breastfed children in our sample were less likely to contract illnesses, thereby compensating - at least in part-for the lack of diet diversity. The continued breastfeeding of children aged 6 to 18 months was linked with significantly lower incidence of both diarrhea and cough. This finding confirms the benefits of continued breastfeeding for children aged between one and two years old, as suggested by the United Nations International Children's Emergency Fund (UNICEF) [44].

Interestingly, we did not find that continued breastfeeding was associated with the incidence of fever or cold. Studies elsewhere have found that breastfeeding may be associated with a lower risk of fever in specific cases, including post-immunization, as well as among children with hand, foot, and mouth disease $[40,45]$. However, we do not know the specific underlying causes of fever in our data. Given that the cause of fever is highly variable, and its relation with breastfeeding is therefore complicated, we cannot identify the reasons for why there were no such correlations in our data. As for the correlation between breastfeeding and cold, one possible reason may be that children in rural areas are exposed to more infectious organisms that may reduce the protective effect of breast milk to a certain extent.

To our knowledge, ours is the first study using longitudinal data to examine the relationship between continued breastfeeding and child illness in poor rural counties in China. It was based on a large sample of children, representative of poor counties in northern China.

One limitation of this study is that because our data on child feeding practices is based on caregiver recall, we cannot rule out the possibility of recall bias. Also, although we attempted to sample villages that varied in terms of household income, population size, distance from county seat, and geographic location, it is possible that the sample is not representative of all households throughout all of rural China.

In conclusion, we find that continued breastfeeding after 6 months can help to provide protection against diarrhea and cough. We also find, however, that the practice of continued breastfeeding in rural China is uncommon, especially after one year of age. A qualitative study conducted in the southern part of Shaanxi Province suggests that a lack of information on healthy feeding practices and a poor understanding of the nutritional contents of food may be behind these suboptimal feeding practices [43]. Our results indicate that efforts should be made to improve the quality of information available to caregivers of young children and increase the rate of continued breastfeeding in both rural China and other low-resource settings in order to improve child health. One method of doing so might be to launch a series of public health and nutrition campaigns in rural areas, as such efforts have been shown to improve caregivers' feeding practices [46]. Community health worker programs have also been effective in other contexts [47-49], and some evidence suggests that such an approach may show promise in rural China as well [50]. Any campaign should provide specific child-feeding information, such as the importance of continued breastfeeding and dietary diversity for children's health and development, and how to provide children with a rich diet.

Author Contributions: Conceptualization, S.L.; Project administration, S.L., A.Y., A.M. and Y.S.; Writing一review \& editing, S.L., C.A. and A.M.

Funding: This research was funded by the Fundamental Research Funds for the Central Universities (2017TS054); the 111 project (Grant number: B16031), the National Natural Science Foundation of China (Grant No. 71703083), the International Initiative for Impact Evaluation (3ie), UBS Optimus Foundation.

Conflicts of Interest: The authors declare no conflict of interest. 


\section{Appendix A}

Table A1. Variables description.

\begin{tabular}{|c|c|}
\hline Variables & Description \\
\hline \multicolumn{2}{|l|}{ Panel A. Child Characteristics } \\
\hline Gender ( 1 = Male, 0 = Female $)$ & Child's gender \\
\hline Age (months) & Child's age in months \\
\hline Has siblings $(1=$ Yes, $0=\mathrm{No})$ & Child has siblings from the same parents \\
\hline Premature Birth $(1=$ Yes, $0=$ No $)$ & Child was born prior to 37 weeks of gestation \\
\hline Mother is the primary caregiver $(1=$ Yes, $0=\mathrm{No})$ & Mother is primarily responsible for the child's care \\
\hline \multicolumn{2}{|l|}{ Panel B. Household Characteristics } \\
\hline Maternal Age $>25(1=$ Yes, $0=$ No $)$ & Whether mother's age is above or below 25 years \\
\hline Maternal Education ( $1 \geq 9$ years, $0 \leq 9$ years) & $\begin{array}{l}\text { Whether mother has received any high school } \\
\text { education }\end{array}$ \\
\hline Paternal Education ( $1 \geq 9$ years, $0 \leq 9$ years $)$ & $\begin{array}{l}\text { Whether father has received any high school } \\
\text { education }\end{array}$ \\
\hline Father lives at Home $(1=$ Yes, $0=\mathrm{No})$ & Whether father lives at home with the child \\
\hline Grandmother is Healthy $(1=$ Yes, $0=\mathrm{No})$ & Health status of grandmother \\
\hline Grandmother Education ( $1 \geq 6$ years, $0 \geq 6$ years) & $\begin{array}{l}\text { Whether grandmother has received any middle } \\
\text { school education }\end{array}$ \\
\hline Household Asset Index & $\begin{array}{l}\text { Index for durable goods (assets) owned by the } \\
\text { household }\end{array}$ \\
\hline $\begin{array}{l}\text { Family Receives Minimum Living Standard } \\
\text { Guarantee Payments }(1=\text { Yes, } 0=\text { No })\end{array}$ & $\begin{array}{l}\text { Whether family receives social security support from } \\
\text { the government (a measure of poverty) }\end{array}$ \\
\hline \multicolumn{2}{|l|}{ Panel C. Feeding Behaviors } \\
\hline Exclusive Breastfeeding & Child was fed only through breastfeeding \\
\hline Non-exclusive Breastfeeding, without Formula & $\begin{array}{l}\text { Child was fed through breastfeeding and food (no } \\
\text { formula) }\end{array}$ \\
\hline Non-exclusive Breastfeeding, with Formula and Food & $\begin{array}{l}\text { Child was fed through breastfeeding, food, and } \\
\text { formula }\end{array}$ \\
\hline Formula with Food & $\begin{array}{l}\text { Child was fed through food and formula (no } \\
\text { breastfeeding) }\end{array}$ \\
\hline Food Alone & Child was fed only through food \\
\hline Dietary diversity & $\begin{array}{l}\text { Number of different food types child had consumed } \\
\text { the previous day (according to WHO food categories) }\end{array}$ \\
\hline \multicolumn{2}{|l|}{ Panel D. Health Outcomes } \\
\hline $\begin{array}{l}\text { Child had a fever in the past month } \\
(1=\text { Yes, } 0=\text { No })\end{array}$ & $\begin{array}{l}\text { Caregiver recalls child having a fever in the month } \\
\text { prior to survey administration }\end{array}$ \\
\hline $\begin{array}{l}\text { Child had diarrhea in the past month } \\
(1=\text { Yes, } 0=\text { No })\end{array}$ & $\begin{array}{l}\text { Caregiver recalls child having diarrhea in the month } \\
\text { prior to survey administration }\end{array}$ \\
\hline $\begin{array}{l}\text { Child had a cold in the past month } \\
(1=\text { Yes, } 0=\text { No })\end{array}$ & $\begin{array}{l}\text { Caregiver recalls child having a cold in the month } \\
\text { prior to survey administration }\end{array}$ \\
\hline $\begin{array}{l}\text { Child had a cough in the past month } \\
(1=\text { Yes, } 0=\text { No })\end{array}$ & $\begin{array}{l}\text { Caregiver recalls child having a cough in the month } \\
\text { prior to survey administration }\end{array}$ \\
\hline
\end{tabular}


Table A2. Summary statistics of outcomes and covariates by attrition status.

\begin{tabular}{|c|c|c|c|c|c|}
\hline & & Full Sample & $\begin{array}{l}\text { Attrited } \\
\text { Sample }\end{array}$ & $\begin{array}{l}\text { Non-Attrited } \\
\text { Sample }\end{array}$ & $\begin{array}{l}\text { Difference: } \\
\text { (2)-(3) }\end{array}$ \\
\hline & & $\begin{array}{c}\text { Mean } \\
\text { Standard } \\
\text { Deviation }\end{array}$ & $\begin{array}{c}\text { Mean } \\
\text { Standard } \\
\text { Deviation }\end{array}$ & $\begin{array}{c}\text { Mean } \\
\text { Standard } \\
\text { Deviation }\end{array}$ & $p$-Value \\
\hline & & (1) & (2) & (3) & (4) \\
\hline \multicolumn{6}{|c|}{ Health outcomes } \\
\hline (1) & $\begin{array}{l}\text { Child had a fever in } \\
\text { the past month }\end{array}$ & $0.30(0.46)$ & $0.30(0.46)$ & $0.30(0.46)$ & 0.994 \\
\hline (2) & $\begin{array}{l}\text { Child had diarrhea } \\
\text { in the past month }\end{array}$ & $0.37(0.48)$ & $0.36(0.48)$ & $0.37(0.48)$ & 0.717 \\
\hline (3) & $\begin{array}{l}\text { Child had a cold in } \\
\text { the past month }\end{array}$ & $0.57(0.50)$ & $0.56(0.50)$ & $0.57(0.50)$ & 0.717 \\
\hline (4) & $\begin{array}{l}\text { Child had a cough in } \\
\text { the past month }\end{array}$ & $0.45(0.50)$ & $0.47(0.50)$ & $0.45(0.50)$ & 0.707 \\
\hline \multicolumn{6}{|c|}{ Characteristics of infant } \\
\hline (5) & Breastfeeding & $0.58(0.49)$ & $0.62(0.49)$ & $0.58(0.49)$ & 0.249 \\
\hline (6) & Dietary diversity & $3.00(1.20)$ & $2.99(1.06)$ & $3.00(1.20)$ & 0.916 \\
\hline
\end{tabular}

Notes: Data source is authors' survey. Descriptive statistics of child and household characteristics when children are 6-12 months of age. The first column shows the mean and standard deviation of each characteristic for the full sample; column 2 shows the characteristics of sample children who attrited between baseline and endline; and column 3 show the characteristics of children in the sample after attrition.

\section{References}

1. UNICEF. Tracking Progress for Breastfeeding Policies and Programmes. 2017.

2. Horta, B.; Bahl, R.; Martines, J.; Victora, C. Evidence on the Long-Term Effects of Breastfeeding: Systematic Reviews and Meta-Analyses; World Health Organization: Geneva, Switzerland, 2007; pp. 1-52.

3. Liu, J.; Shi, Z.; Spatz, D.; Loh, R.; Sun, G.; Grisso, J. Social and demographic determinants for breastfeeding in a rural, suburban and city area of South East China. Contemp. Nurse 2012, 1, 233-245.

4. Lamberti, L.M.; Fischer Walker, C.L.; Noiman, A.; Victora, C.; Black, R.E. Breastfeeding and the risk for diarrhea morbidity and mortality. BMC Public Health 2011, 11. [CrossRef]

5. Bhandari, N.; Mazumder, S.; Bahl, R.; Martines, J.; Black, R.E. An Educational Intervention to Promote Appropriate Complementary Feeding Practices and Physical Growth in Infants and Young Children in Rural Haryana, India. J. Nutr. 2004, 134, 2342-2348. [CrossRef] [PubMed]

6. Duijts, L.; Jaddoe, V.W.V.; Hofman, A.; Moll, H.A. Prolonged and Exclusive Breastfeeding Reduces the Risk of Infectious Diseases in Infancy. Pediatrics 2010, 126, e18-e25. [CrossRef] [PubMed]

7. Kramer, M.S.; Kakuma, R. Optimal duration of exclusive breastfeeding. Cochrane Database Syst. Rev. 2002. [CrossRef]

8. Xu, F.; Qiu, L.; Binns, C.W.; Liu, X. Breastfeeding in China: A review. Int. Breastfeed. J. 2009, 4, 1-15. [CrossRef] [PubMed]

9. Guo, S.; Fu, X.; Scherpbier, R.W.; Wang, Y.; Zhou, H.; Hipgrave, D.B. Breastfeeding rates in central and western China in 2010: Implications for child and population health. Bull. World Health Organ. 2013, 322-331. [CrossRef]

10. Yang, Z.; Lai, J.; Yu, D.; Duan, Y.; Pang, X.; Jiang, S.; Bi, Y.; Wang, J.; Zhao, L.; Yin, S. Breastfeeding rates in China: A cross-sectional survey and estimate of benefits of improvement. Lancet 2016, 388, S47. [CrossRef]

11. Wang, X.; Wang, Y.; Kang, C. Feeding practices in 105 counties of rural China. Child. Care. Health Dev. 2005. [CrossRef]

12. Liu, P.; Qiao, L.; Xu, F.; Zhang, M.; Wang, Y.; Binns, C.W. Factors associated with breastfeeding duration: A 30-month cohort study in Northwest China. J. Hum. Lact. 2013, 29, 253-259. [CrossRef] [PubMed] 
13. Lauer, J.A.; Betrán, A.P.; Victora, C.G.; de Onís, M.; Barros, A.J.D. Breastfeeding patterns and exposure to suboptimal breastfeeding among children in developing countries: Review and analysis of nationally representative surveys. BMC Med. 2004, 2. [CrossRef]

14. World Health Organization. Global Strategy for Infant and Young Child Feeding, 2003.

15. Agostoni, C.; Bergman, R.; Bresson, J.-L.; Michaelsen, K.F.; Przyrembel, H.; Sanz, Y.; Tomé, D. Scientific opinion on the appropriate age for introduction of complementary feeding of infants. EFCA 2009, 7, 1-38. [CrossRef]

16. Brown, K.; Peerson, J.; Kimmons, J.; Hotz, C. Options for achieving adequate intake from home-prepared complementary foods in low income countries. In Public health Issues in Infant and Child Nutrition; Lippincott Williams \& Wilkins: Philadelphia, PA, USA, 2002.

17. Arimond, M.; Ruel, M.T. Dietary Diversity Is Associated with Child Nutritional Status: Evidence from 11 Demographic and Health Surveys. J. Nutr. 2004, 134, 2579-2585. [CrossRef] [PubMed]

18. Arimond, M.; Ruel, M.T. Progress in Developing an Infant and Child Feeding Index: An Example Using the Ethiopia Demographic and Health Survey 2000. Food Consum. Nutr. Div. 2002. [CrossRef]

19. Roy, S.K.; Fuchs, G.J.; Mahmud, Z.; Ara, G.; Islam, S.; Shafique, S.; Akter, S.S.; Chakraborty, B.; Roy, A.S.K.; Fuchs, G.J.; et al. Intensive Nutrition Education with or without Supplementary Feeding Improves the Nutritional Status of Moderately-malnourished Children in Bangladesh. J. Health. Popul. Nutr. 2005, $23,321$.

20. Irarrázaval, B.; Barja, S.; Bustos, E.; Doirsaint, R.; Senethmm, G.; Guzmán, M.P.; Uauy, R. Influence of feeding practices on malnutrition in Haitian infants and young children. Nutrients 2018, 10, 382. [CrossRef] [PubMed]

21. Zaragoza Cortes, J.; Trejo Osti, L.E.; Ocampo Torres, M.; Maldonado Vargas, L.; Ortiz Gress, A.A. Poor breastfeeding, complementary feeding and Dietary Diversity in children and their relationship with stunting in rural communities. Nutr. Hosp. 2018. [CrossRef]

22. Zhang, J.; Shi, L.; Wang, J.; Wang, Y. An infant and child feeding index is associated with child nutritional status in rural China. Early Hum. Dev. 2009. [CrossRef]

23. Wang, Y.; Zhu, J.; He, C.; Li, X.; Miao, L.; Liang, J. Geographical disparities of infant mortality in rural China. Arch. Dis. Child. Fetal Neonatal Ed. 2012, 97. [CrossRef]

24. Tang, S.; Meng, Q.; Chen, L.; Bekedam, H.; Evans, T.; Whitehead, M. Tackling the challenges to health equity in China. Lancet 2008. [CrossRef]

25. Liu, H.; Fang, H.; Zhao, Z. Urban-rural disparities of child health and nutritional status in China from 1989 to 2006. Econ. Hum. Biol. 2013. [CrossRef] [PubMed]

26. Wang, X.-Y.; Xu, Z.-Y.; von Seidlein, L.; Zhang, Y.-L.; Zhao, S.-J.; Hao, Z.-Y.; Han, O.P.; Kilgore, P.; Xing, Z.-C.; Han, C.-Q.; et al. Incidence of diarrhea caused by rotavirus infections in rural Zhengding, China: Prospective, population-based surveillance. J. Infect. Dis. 2005, 192, S100-S105. [CrossRef] [PubMed]

27. Shah, S.M.; Yousafzai, M.; Lakhani, N.B.; Chotani, R.A.; Nowshad, G. Prevalence and correlates of diarrhea. Indian J. Pediatr. 2003. [CrossRef]

28. Mbonye, A.K. Prevalence of Childhood Illnesses and Care-Seeking Practices in Rural Uganda. Sci. World J. 2003. [CrossRef] [PubMed]

29. Huang, C.; Liu, W.; Hu, Y.; Zou, Z.; Zhao, Z.; Shen, L.; Weschler, L.B.; Sundell, J. Updated prevalences of asthma, allergy, and airway symptoms, and a systematic review of trends over time for childhood asthma in shanghai, China. PLoS ONE 2015. [CrossRef] [PubMed]

30. Yarnoff, B.O.; Allaire, B.T.; Detzel, P. Associations between Infant Feeding Practices and Length, Weight, and Disease in Developing Countries. Front. Pediatr. 2013. [CrossRef] [PubMed]

31. World Bank. World Development Indicators 2014; World Bank: Washington, UK, 2014; ISBN 978-1-4648-0163-1.

32. Shaanxi Bureau of Statistics of China. Shaanxi Statistical Yearbook; China Statistics Press: Beijing, China, 2014; ISBN 7503771828.

33. National Bureau of Statistics of China. China Statistical Yearbook. 2014.

34. Luo, R.; Yue, A.; Zhou, H.; Shi, Y.; Zhang, L.; Martorell, R.; Medina, A.; Rozelle, S.; Sylvia, S. The effect of a micronutrient powder home fortification program on anemia and cognitive outcomes among young children in rural China: A cluster randomized trial. BMC Public Health 2017, 17, 1-16. [CrossRef]

35. Luo, R.; Shi, Y.; Zhou, H.; Yue, A.; Zhang, L.; Sylvia, S.; Medina, A.; Rozelle, S. Anemia and feeding practices among infants in rural Shaanxi Province in China. Nutrients 2014. [CrossRef]

36. World Health Organization. Indicators for Assessing Infant and Young Child Feeding Practices: Part 1 Definitions; WHO Press: Geneva, Switzerland, 2008; ISBN 9789241596664. 
37. World Health Organization. Indicators for Assessing Infant and Young Child Feeding Practices: Part 2 Measurement; WHO Press: Geneva, Switzerland, 2010; ISBN 9789241599290.

38. Daelmans, B.; Dewey, K.; Arimond, M. New and updated indicators for assessing infant and young child feeding. Food Nutr. Bull. 2009. [CrossRef]

39. Zhou, X.; Fang, J.; Luo, J.; Wang, H.; Du, Q.; Huang, G.; Feng, B.; Quan, Q. Influential factors associated with 2-week prevalence of fever and diarrhea among infants and young children at the age of 6-23 months in poor rural areas. J. Cent. South. Univ. 2017, 42, 1072-1079. [CrossRef]

40. Pisacane, A.; Continisio, P.; Palma, O.; Cataldo, S.; De Michele, F.; Vairo, U. Breastfeeding and Risk for Fever After Immunization. Pediatrics 2010, 125, e1448-e1452. [CrossRef] [PubMed]

41. United Nations Children's Fund (UNICEF). Progress for Every Child in the SDG Era; UNICEF: New York, NY, USA, 2018; pp. 1-106.

42. Onyango, A.; Koski, K.G.; Tucker, K.L. Food diversity versus breastfeeding choice in determining anthropometric status in rural Kenyan toddlers. Int. J. Epidemiol. 1998. [CrossRef]

43. Yue, A.; Marsh, L.; Zhou, H.; Medina, A.; Luo, R.; Shi, Y.; Zhang, L.; Kenny, K.; Rozelle, S. Nutritional deficiencies, the absence of information and caregiver shortcomings: A qualitative analysis of infant feeding practices in rural China. PLoS ONE 2016. [CrossRef] [PubMed]

44. WHO. Global Strategy on Infant and Young Child Feeding; World Health Organizaion: Geneva, Switzerland, 2003.

45. Zhu, Q.; Li, N.; Han, Q.; Liu, Z.; Li, Z.; Zhang, G.; Li, F.; Tian, N.; Li, Y.; Qiu, J. Prolonged exclusive breastfeeding, autumn birth and increased gestational age are associated with lower risk of fever in children with hand, foot, and mouth disease. Eur. J. Clin. Microbiol. Infect. Dis. 2012, 31, 2197-2202. [CrossRef] [PubMed]

46. Shi, L.; Zhang, J.; Wang, Y.; Caulfield, L.E.; Guyer, B. Effectiveness of an educational intervention on complementary feeding practices and growth in rural China: A cluster randomised controlled trial. Public Health Nutr. 2010, 13, 556-565. [CrossRef]

47. Gilmore, B.; McAuliffe, E. Effectiveness of community health workers delivering preventive interventions for maternal and child health in low- and middle-income countries: A systematic review. BMC Public Health 2013, 13. [CrossRef]

48. Gogia, S.; Sachdev, H.S. Des visites á domicile par des professionnels communautaires de la santé permettent de réduire la mortalité infantile dans les pays en voie de développement: Une revue systématique. Bull. World Health Organ. 2010, 88, 658-666. [CrossRef] [PubMed]

49. Avellar, S.A.; Supplee, L.H. Effectiveness of Home Visiting in Improving Child Health and Reducing Child Maltreatment. Pediatrics 2013, 132, S90-S99. [CrossRef] [PubMed]

50. From Quantity to Quality: Delivering a Home-based Parenting INtervention through China's Family Planning Cadres. Available online: https:/ / feb.kuleuven.be/drc/licos/publications/dp/DP\%20402.pdf (accessed on 04 January 2019). 